\title{
La Perfección de Eça de Queiroz
}

Traducción de Kristbian Ayala

Resumen: El texto es una traducción directa del portugués del relato La perfección de Eça de Queiroz. Este cuento de tema mitológico se aparta de los tópicos del naturalismo en el cual destacó el célebre escritor portugués de fines del siglo XIX.

Palabras clave: Mitología, narrativa portuguesa, siglo XIX

Abstract: The text is a direct translation of the Brazilian story La Perfección by Eça de Queiroz. This story of mythological nature departs from the topics of naturalism in which the famous late 19th century Brazilian writer stood out.

Keywords: Mythology, Portuguese narrative, nineteenth century

entado en una roca, en la isla de Ogigia, con la barba enterrada entre las manos, de
donde desapareciera la esperanza callosa y tiznada de las armas y de los remos, Ulises, el más sutil de los hombres, consideraba, en una oscura y pesada tristeza, sobre el mar muy azul que, mansa y armoniosamente, se deslizaba sobre la arena muy blanca. Una túnica bordada de flores escarlatas cubría, en pliegues lánguidos, su cuerpo poderoso que había engordado. En las correas de las sandalias, que le calzaban los pies, suavizados y perfumados de esencias, relucían esmeraldas de Egipto. Y su bastón era un maravillosa rama de coral, rematada en una piña de perlas, como el que usan los dioses marinos.

La divina isla, con sus rocas de alabastro, los bosques de cedros y tuyas odoríferas, las mieses eternas dorando los valles, la frescura de los rosales revistiendo los cerros delicados, resplandecía, adormecida en la languidez de la siesta, toda en vuelta en mar resplandeciente. $\mathrm{Ni}$ un soplo de los céfiros curiosos, que juegan y corren sobre el archipiélago, perturbaba la serenidad del luminoso aire, más dulce que el vino más dulce, todo repasado por el fino 
aroma de los prados de violetas. En el silencio, embebido de calor afable, eran de la armonía más encantadora los murmullos de arroyos y fuentes, el arrullar de las palomas volando de los cipreses a los plátanos, el lento deslizarse y quebrar de la ola mansa sobre la arena suave. Y en esa inefable paz y belleza inmortal, el sutil Ulises, con los ojos perdidos en las aguas lustrosas, amargamente gemía, revolviendo la quejumbre de su corazón.

Siete años, siete inmensos años, habían pasado desde que el rayo fulgente de Júpiter hendiera su nave de alta proa roja, y él, agarrado al mástil partido, había rodado en la braveza mugidora de las espumas sombrías, durante nueve días, durante nueve noches, hasta que boyara en aguas calmadas y tocara las arenas de aquella isla donde Calipso, la diosa radiante, lo había recogiera y amara. Y durante esos inmensos años, ¿como se fue arrastrando su vida, su gran y fuerte vida, que, después de la partida hacia los muros fatales de Troya, abandonando entre lágrimas incontables a su Penélope de ojos claros, a su pequeño Telémaco, enfajado, al cuello de la ama, anduvo siempre tan agitada por peligros, y guerras, y astucias, y tormentas, y rumbos perdidos? ¡Ah, dichosos los reyes muertos, con hermosas heridas en el blanco pecho, delante de las puertas de Troya! ¡Felices sus compañeros tragados por la ola amarga! ¡Feliz él si las lanzas troyanas lo hubieran traspasado esa tarde de gran viento y polvo, cuando, junto al Haya, defendía de los ultrajes, con la espada sonora, el cuerpo muerto de Aquiles! ¡Pero no! ¡Vivió! ¡Y ahora, cada mañana, al salir sin alegría del trabajoso lecho de Calipso, las Ninfas, siervas de la diosa, lo bañaban en aguas muy puras, perfumaban de lánguidas esencias, lo cubrían con una túnica siempre nueva, ora bordada de sedas finas, ora bordada de oro pálido! Mientras tanto, sobre la mesa lustrosa, erguida a la puerta de la gruta, en la sombra de las enramadas, junto al susurro durmiente de un arroyo diamantino, los azafates y las fuentes cinceladas transbordaban de tortas, de frutas, de tiernas carnes humeantes, de pescados centellando como tramas de plata. La intendenta venerable helaba los vinos dulces en las cráteras de bronce coronadas de rosas. Y él, sentado en un escabel, extendía las manos hacia los manjares perfectos, mientras al otro lado, sobre un trono de marfil, Calipso, esparciendo a través de la túnica nevada la claridad y el aroma de su cuerpo inmortal, sublimemente serena con una sonrisa taciturna, sin tocar los alimentos humanos, picoteaba la ambrosía, bebía en sorbos delicados el néctar transparente y rubro. Después, tomando aquel bastón del Príncipe de Pueblos, que Calipso le había regalado, recorría sin curiosidad los conocidos caminos de la isla, tan lisos y tratados que nunca sus sandalias relucientes se ensuciaban de polvo, tan penetrados por la inmortalidad de diosa que jamás en ellos encontraría hoja seca, ni flor menos fresca pendiendo del tallo. Sobre 
una roca se sentaba entonces, contemplando aquel mar que también bañaba Ítaca, allá tan bravío, aquí tan sereno, y pensaba, y gemía, hasta que las aguas y los caminos se cubrían de sombra, y él se recogía en la gruta para dormir, sin deseo, con la diosa que lo deseaba... Y durante esos inmensos años, ¿qué destino habría envuelto a su Ítaca, la áspera isla de sombríos bosques? ¿vivían aún ellos, sus seres amados? Sobre la fuerte colina, dominando la ensenada de Reitros y los pinares de Neus, ¿todavía se erguía su palacio, con los bellos pórticos pintados de rojo y cárdeno? Al cabo de tan lentos y vacíos años, sin noticias, eliminada toda esperanza como una lámpara, ¿se habría despojado su Penélope de la túnica pasajera de la viudez, y habría pasado a los brazos de otro esposo fuerte que, ahora, manejaba sus lanzas y vendimiaba sus viñas? ¿Y el dulce hijo Telémaco? ¿Reinaría él en Ítaca, sentado, con el cetro blanco, sobre el mármol alto del ágora? Ocioso y rondando por los patios, ¿entornaría los ojos sobre el imperio duro de un padrastro? ¿Erraría por ciudades ajenas, mendigando un salario?... ¡Ah! ¡Si su existencia, así para siempre arrancada de la mujer, del hijo, tan dulces a su corazón, estuviese al menos empleada en hazañas ilustres! Diez años antes también desconocía la suerte de Ítaca, y de los seres preciosos que allí había dejado en soledad y fragilidad; pero una empresa heroica lo agitaba; y cada mañana su fama crecía como un árbol en un promontorio que llena el cielo y todos los hombres contemplan. ¡Entonces era la planicie de Troya ¡y las blancas tiendas de los griegos a lo largo del mar sonoro! ¡Sin cesar meditaba las astucias de la guerra; con soberbia facundia discurseaba en la Asamblea de los Reyes; rigurosamente uncía los caballos empinados al timón de los carros; con la lanza en alto corría, entre prisas y griterío, contra los troyanos de altos yelmos, que surgían, en tropel retumbante, de las puertas Skaias!... ¡Oh! ¡Y cuando él, Príncipe de Pueblos, encogido bajo harapos de mendigo, con los brazos maculados de llagas postizas, cojeando y gimiendo, había penetrado en los muros de la orgullosa Troya, por el lado del Haya, para, de noche, con incomparable ardid y bravura, robar el paladión tutelar de la ciudad! Y cuando, dentro del vientre del Caballo de Madera, en la oscuridad, en el aprieto de todos aquellos guerreros yertos y cubiertos de hierro, calmaba la impaciencia de los que sofocaban, y tapaba con la mano la boca de Anticlos clamando furioso, al escuchar fuera en la llanura los ultrajes y los escarnios troyanos, y a todos murmuraba: « Calla, calla! que ya cae la noche y Troya es nuestra...» ¡Y después los prodigiosos viajes! El pavoroso Polifemo, escarnecido con una astucia que para siempre maravillará a generaciones! ¡Las maniobras sublimes entre Escila y Caribdis! ¡Las Sirenas, bogando y cantando en torno al mástil, en donde él, amarrado, las rechazaba con el mudo dardear de los ojos más agudos que dardos! ¡El descenso a los 
infiernos, jamás concedido a un mortal!... ¡Y ahora hombre de tan rutilantes hechos yacía en una isla indolente, eternamente preso, sin amor, por el amor de una diosa! ¿Cómo podré él huir, rodeado de mar indomable, sin nave, sin compañeros para mover los largos remos? ¡Los dioses dichosos ciertamente olvidaban lo mucho que por ellos había combatido, y que siempre piadosamente les había dedicado las reses debidas, incluso a través del fragor y humareda de las ciudadelas derrumbadas, incluso cuando su proa encallaba en tierra agreste!... Y al héroe, que había recibido de los reyes de Grecia las armas de Aquiles, cabía por destino amargo engordar en la ociosidad de una isla más lánguida que una cesta de rosas, y extender las manos reblandecidas hacia manjares abundantes y, cuando aguas y caminos se cubrían de sombra, dormir sin deseo con una diosa que, sin cesar, lo deseaba. Así gemía el magnánimo Ulises, a la orilla del mar espléndido... y he aquí que, de repente, un surco, de desusado brillo, más rutilantemente blanco que el de una estrella cayendo, rasgó el esplendor del cielo, desde las alturas hasta la olorosa mata de tuyas y cedros que sombreaba un golfo sereno, al oriente de la isla. ¡El corazón del héroe latió con alborozo! Rastro tan refulgente, en el fulgor del día, solo un dios lo podía trazar a través del gran Urano. ¿Un dios, pues, había bajado a la isla?

U n dios había bajado, un gran dios... Era el mensajero de los dioses, el ligero, elocuente Mercurio. Calzado con aquellas sandalias que tienen dos alas blancas, los cabellos del color del vino cubiertos por el casco donde se agitan también dos claras alas, portando en la mano el caduceo, había hendido el éter, rozado la lisura del mar sosegado, pisado la arena de la isla, en la que sus pisadas quedaban resplandeciendo como plantillas de oro nuevo. A pesar de recorrer toda la tierra, con los recados innumerables de los dioses, el iluminado mensajero no conocía aquella isla de Ogigia, y admiró, sonriendo, la belleza de los prados de violetas, tan dulces para el correr y juguetear de las ninfas, y el armonioso chispear de los regatos entre los altos y lánguidos lirios. Una viña, sobre columnas de jaspe, cargada de racimos maduros, conducía, como fresco pórtico salpicado de sol, hasta la entrada de la gruta, toda de rocas pulidas, de donde pendían jazmines y madreselvas, envueltas en el susurrar de las abejas. Y de pronto vio a Calipso, la diosa feliz, sentada en un trono, hilando en rueca de oro, con huso de oro, la lana hermosa de púrpura marina. Un aro 
de esmeraldas sujetaba sus cabellos ensortijados e ardientemente rubios. Sobre la túnica diáfana la mocedad inmortal de su cuerpo rebrillaba, como la nieve, cuando la aurora la tiñe de rosas en las colinas eternas pobladas de dioses. Y mientras torcía el huso, cantaba un trinado y fino canto, como trémulo hilo de cristal vibrando desde la tierra hasta el cielo. Mercurio pensó: «iPreciosa isla, y preciosa ninfa!».

De un fuego claro de cedro y tuya, subía, muy recto, un humo sutil que perfumaba toda la isla. Alrededor, sentada en esteras, sobre el suelo de ágata, las ninfas, siervas de la diosa, devanaban las lanas, bordaban en la seda las flores ligeras, tejían las puras telas en telares de plata. Todas se ruborizaron, el seno palpitando, al sentir la presencia del dios. Y, sin detener el huso chispeante, Calipso había reconocido inmediatamente al mensajero, ya que todos los inmortales conocen, los unos de los otros, los nombres, los hechos y los rostros soberanos, incluso cuando habitan retiros remotos que el éter y el mar separan.

Mercurio se había parado, risueño, en su desnudez divina, exhalando el perfume del Olimpo. Entonces, la diosa levantó hacia él, con compuesta serenidad, el amplio esplendor de sus ojos verdes:

— $O$ Oh Mercurio! ¿Por qué has descendido a mi humilde isla, tú, venerable y querido, a quien yo nunca vi pisar la tierra? Dime lo que esperas de mí. Ya mi abierto corazón me ordena que te contente, si tu deseo cupiere dentro de mi poder y del hado... Pero entra, reposa, y que yo te sirva, como dulce hermana, a la mesa de la hospitalidad.

Separó la rueca de la cintura, apartó los rizos sueltos de su cabello radiante, y con sus nacaradas manos colocó sobre la mesa, acercada por las ninfas al fuego aromático, el plato rebosante de ambrosía, y los ciborios de cristal en los que centelleaba el néctar.

Mercurio murmuró: «¡Dulce es tu hospitalidad, oh diosa!» Colgó el caduceo en la fresca rama de un plátano, extendió sus dedos relucientes hacia la fuente de oro, risueñamente alabó la excelencia de aquel néctar de la isla. Y, contentada el alma, apoyando la cabeza en el tronco liso del plátano, que se cubrió de claridad, comenzó, con palabras perfectas y aladas:

- Te preguntaste por qué un dios descendía a tu morada, ¡oh diosa! Y ciertamente ningún inmortal recorrería sin motivo, desde el Olimpo hasta Ogigia, esta desierta inmensidad del mar salado en la que no se encuentran ciudades de hombres, ni templos cercados de bosques, ni siquiera un pequeño santuario de donde suba el aroma del incienso, o el olor de las carnes votivas, o el murmullo gustoso de las preces... Pero fue nuestro padre Júpiter, el tempestuoso, el que me mandó este recado. Tú recogiste, y retienes por la 


\section{KRISTHIAN AYALA}

fuerza inconmensurable de tu dulzura, al más sutil y desgraciado de todos los príncipes que combatieron durante diez años la alta Troya, y después embarcaron en las naves hondas para volver a la tierra de la patria. Muchos de esos consiguieron regresar a sus ricos lares, cargados de fama, de botines, y de historias excelentes para contar. Vientos enemigos, sin embargo, y un fado más inexorable, arrojaron a esta tu isla, envuelto en sucias espumas, al facundo y astuto Ulises... Pero el destino de este héroe no es el de quedarse en la ociosidad inmortal de tu lecho, lejos de aquellos que lo lloran, y que carecen de su fuerza y mañas divinas. ¡Por eso Júpiter, regulador del orden, te ordena, oh diosa, que sueltes al magnánimo Ulises de tus brazos claros y lo restituyas, con los regalos dulcemente debidos, a su Ítaca amada, y a su Penélope, que teje y desteje la tela ardilosa, cercada de los pretendientes arrogantes, devoradores de sus gordos bueyes, bebedores de sus frescos vinos.

La divina Calipso se mordió levemente el labio, y sobre su rostro luminoso cayó la sombra de las densas pestañas color jacinto. Después, con un armonioso suspiro, en el que onduló todo su pecho resplandeciente:

—Ah dioses grandes, dioses dichosos, qué ásperamente celosos sois de las diosas, que, sin esconderse por la espesura de los bosques o en los pliegues oscuros de los montes, aman a los hombres elocuentes y fuertes!... Éste, que me envidiáis, rodó a las arenas de mi isla, desnudo, pisado, hambriento, preso a una quilla partida, perseguido por todas las iras, y todas las ráfagas, y todos los rayos hirientes de que dispone el Olimpo. Yo lo recogí, lo lavé, lo nutrí, lo amé, lo guardé, para que quedase eternamente al abrigo de las tormentas, del dolor y de la vejez. Y ahora Júpiter tonante, después de ocho años en los que mi dulce vida se enroscó alrededor de este afecto como la vid al olmo, decide que yo me separe del compañero que había escogido para mi inmortalidad. ¡Realmente sois crueles, oh dioses, que constantemente aumentáis la raza turbulenta de los semidioses durmiendo con las mujeres mortales! ¿Y cómo quieres que yo mande a Ulises a su patria, si no poseo naves, ni remeros, ni piloto sabedor que lo guíe a través de las islas? ¿Pero quién puede resistir a Júpiter, que gobierna las nubes? ¡Sea! Y que el Olimpo se ría, obedecido. Yo enseñaré al intrépido Ulises a construir una lancha segura, con la que de nuevo rasgue el dorso verde del mar...

— ¡Bien harás, oh Calipso! Así evitas la cólera del Padre atronador. ¿Quién se le resistirá? Su omnisciencia dirige su omnipotencia. Y sustenta, como cetro, un árbol que tiene por flor el orden... Sus decisiones, clementes o crueles, resultan siempre en armonía. 
Por eso su brazo se vuelve terrorífico a los pechos rebeldes. Por su pronto sumisión serás hija estimada, y gozarás una inmortalidad impregnada de sosiego, sin intrigas y sin sorpresas.

Ya las alas impacientes de sus sandalias palpitaban, y su cuerpo, con sublime gracias, se balanceaba sobre los céspedes y flores que alfombraban la entrada de la gruta.

-Por lo demás- añadió-, tu isla, oh diosa, queda en el camino de las naves osadas que rasgan las olas. En breve quizás otro héroe robusto, habiendo ofendido a los inmortales, arribará a tu dulce playa, abrazado a una quilla... ¡Enciende una antorcha clara, de noche, en las rocas altas!

Y, riéndose, el mensajero divino serenamente se elevó, rasgando en el éter un surco de elegante fulgor que las ninfas, olvidada la tarea, seguían, con los frescos labios entreabiertos y el seno alzado, deseosas de aquel inmortal famoso.

Entonces, Calipso, pensativa, lanzando sobre sus cabellos rizados un velo del color del azafrán, caminó hacia la orla del mar, a través de los prados, con una prisa que le enredaba la túnica, a manera de una espuma leve, alrededor de las piernas redondas y rosáceas. Tan levemente pisó la arena que el magnánimo Ulises no la sintió deslizarse, perdido en la contemplación de las aguas brillantes, con la negra barba entre las manos, aliviando con gemidos el peso de su corazón. La diosa sonrió, con fugitiva y soberana amargura. Después, posando en el robusto hombro del héroe sus dedos tan claros como los de Eos, madre del día:

- iNo te lamentes más, desgraciado, ni te consumas mirando al mar! Los dioses, que son superiores a mí por la inteligencia y por la voluntad, deciden que tú partas, afrontes la inconstancia de los vientos, y calques de nuevo la tierra de la patria...

Bruscamente, como el cóndor cayendo sobre la presa, el divino Ulises, con el rostro asombrado, saltó de la roca musgosa:

— ¡Oh diosa, tú dices!...

Ella continuó sosegadamente, con los hermosos brazos pendidos, enredados en el velo color azafrán, mientras la ola rodaba, más dulce y cantante, en el amoroso respeto de su presencia divina:

-Bien sabes que no tengo naves de alta proa, ni remadores de recio pecho, ni piloto amigo de las estrellas, que te conduzcan... Pero ciertamente te confiaré el hacha de bronce que fue de mi padre, para que tú tales los árboles que yo te designe y construyas una lancha en la que embarques... Después, la proveeré de odres de vino, de comidas perfectas, y la impeleré con un soplo amigo hacia el mar indómito... 


\section{KRISTHIAN AYALA}

El cauteloso Ulises retrocedió lentamente, clavando en la diosa una dura mirada que la desconfianza oscurecía. Y levantando la mano, que temblaba toda con la ansiedad de su corazón:

- ¡Oh diosa, tú albergas un pensamiento terrible, puesto que así me invitas a afrontar en una lancha las olas difíciles, en las que mal se mantienen hondas naves! ¡No, diosa peligrosa, no! ¡Yo combatí en la gran guerra en la que los dioses también combatieron, y conozco la malicia infinita que contiene el corazón de los inmortales! ¡Si resistí a las sirenas irresistibles, y me salvé con sublimes maniobras de entre Escila y Caribdis, y vencí a Polifemo con un ardid que eternamente me hará ilustre entre los hombres, no fue seguramente, oh diosa, para que ahora, en la isla de Ogigia, como pajarillo de poco plumaje, en su primer vuelo del nido, caiga en la trampa ligera preparada con decires de miel! ¡No, diosa, no! ¡Solo embarcaré en tu extraordinaria barcaza si tú juras, con el juramento terrífico de los dioses, que no tramas, con esos quietos ojos, mi pérdida irreparable!

Así clamaba, a la orilla de las olas, el pecho jadeando, Ulises, el héroe prudente... Entonces la diosa clemente se rió, con una cantarina y refulgente risa. Y caminando hacia el héroe, pasando los dedos celestes por sus espesos cabellos más negros que la pez:

— ¡Oh maravilloso Ulises - dijo-, tú eres, bien es verdad, el más traicionero y engañoso de los hombres, pues ni concibes que exista espíritu sin artificio y sin falsedad! ¡Mi ilustre padre no me engendró con un corazón de hierro! A pesar de inmortal, comprendo las desventuras mortales. Solo te he aconsejado lo que yo, diosa, emprendería, si el Fado me obligase a salir de Ogigia a través del mar incierto...

El divino Ulises retiró lenta y sobriamente la cabeza de la rosada caricia de los dedos divinos:

—Pero jura... ¡Oh diosa, jura, para que a mi pecho descienda, como ola de leche, la sabrosa confianza!

Ella levantó el claro brazo al azul donde los dioses moran:

- Por Gea y por el Cielo superior, y por las aguas subterráneas de Estigia, que es la mayor invocación que pueden lanzar los inmortales, juro, oh hombre, Príncipe de los Hombres, que no tramo tu pérdida ni miserias mayores...

El valiente Ulises respiró hondamente. Y arremangando enseguida las mangas de la túnica, restregando las palmas de las manos robustas:

— ¿En dónde está el hacha de tu padre magnífico? ¡Enséñame los árboles, oh diosa!... ¡El día cae y el trabajo es grande! 
— ¡Calma, oh hombre impaciente de males humanos! Los dioses superiores en sapiencia ya determinaron tu destino... Recógete conmigo en la dulce gruta, a reforzar tu fuerza... Cuando Eos rojiza aparezca, mañana, yo te conduciré a la floresta.

$\mathrm{E}$ ra, en efecto, la hora en la que los hombres mortales y los dioses inmortales se acercan a las mesas cubiertas de vajillas, en donde los espera la abundancia, el reposo, el olvido de los cuidados, y las amorosas conversaciones que contentan el alma. Pronto Ulises se sentó en el escabel de marfil, que todavía conservaba el aroma del cuerpo de Mercurio, y ante él, las ninfas, siervas de la diosa, colocaron los pasteles, las frutas, las tiernas carnes humeantes, los pescados refulgentes como tramas de plata. Posada en trono de oro puro, la diosa recibió de la intendenta venerable el plato de ambrosía y la copa de néctar. Ambos extendieron las manos hacia las comidas perfectas de la tierra y del cielo. E inmediatamente después de dar la ofrenda abundante al hambre y a la sed, la ilustre Calipso, apoyando el rostro en sus dedos rosáceos, y considerando pensativamente al héroe, soltó estas palabras aladas:

- ¡Oh Ulises muy sutil, tú quieres volver a tu morada mortal y a la tierra de la patria!... ¡Ah! Si tú supieses, como yo, qué duros males tiene que sufrir antes de avistar las rocas de Ítaca, quedarías entre mis brazos, animado, bañado, bien nutrido, revestido de finos linos, sin perder nunca la querida fuerza, ni la agudeza del entendimiento, ni el calor de la facundia, puesto que yo te comunicaría mi inmortalidad... Pero deseas volver a la esposa mortal, que habita en la isla áspera en donde los bosques son tenebrosos. Y además no soy inferior a ella, ni por la belleza, ni por la inteligencia, porque las mortales brillan ante las inmortales como lámparas humeantes ante estrellas puras...

El facundo Ulises acarició su ruda barba. Después, levantando el brazo, como solía en la Asamblea de los Reyes, a la sombra de las altas popas, ante los muros de Troya:

- ¡Oh Diosa venerable, no te escandalices! Perfectamente sé que Penélope es muy inferior a ti en hermosura, sapiencia y majestad. Tú serás eternamente bella y joven, mientras los dioses duren: y ella, en pocos años, conocerá la melancolía de las arrugas, de los cabellos blancos, de los dolores de la decrepitud, y de los pasos que tiemblan apoyados en un bastón que tiembla. Su espíritu mortal anda errante a través de la oscuridad y de la duda; tú, bajo esa frente luminosa, posees las luminosas certezas. ¡Pero, oh diosa, justamente por lo que ella 
tiene de incompleto, de frágil, de grosero y de mortal, yo la amo, y apetezco su compañía congénere! ¡Considera lo penoso que es que en esta mesa, cada día, yo coma vorazmente el cordero de los pastos y la fruta de los vergeles, mientras tú a mi lado, por la inefable superioridad de tu naturaleza, llevas a los labios, con lentitud soberana, la ambrosía divina! En ocho años, oh diosa, nunca tu rostro se iluminó con una alegría; ni de tus ojos verdes rodó una lágrima; ni golpeaste el pie, con ira impaciente, ni, gimiendo con un dolor; te extendiste en el lecho blando. Y así traes inutilizadas todas las virtudes de mi corazón, pues tu divinidad no permite que yo me congratule contigo, te consuele, te tranquilice, o incluso frote tu cuerpo dolorido con el jugo de hierbas benéficas. ¡Considera aún que tu inteligencia de diosa posee todo el saber, alcanza siempre la verdad; y, durante el largo tiempo que contigo dormí, nunca gocé la felicidad de enmendarte, de contradecirte, y de sentir, ante la flaqueza del tuyo, la fuerza de mi entendimiento! ¡Oh diosa, tú eres aquel ser terrífico que siempre tiene razón! Considera todavía que, como diosa, conoces todo el pasado y todo el futuro de los hombres: iy yo no pude saborear la incomparable delicia de contarte por la noche, bebiendo el vino fresco, mis ilustres hazañas y mis viajes sublimes! Oh diosa, tú eres impecable: y cuando yo resbale en una alfombra extendida, o reviente una correa de mi sandalia, no te puedo gritar, como los hombres mortales gritan a las esposas mortales: $«_{\mathrm{i}} \mathrm{Ha}$ sido culpa tuya, mujer!», levantando frente a la chimenea un alarido cruel. ¡Por eso sufriré, con un espíritu paciente, todos los males con que los dioses me asalten en el sombrío mar, para volver a una humana Penélope a la que yo mande, y consuele, y reprenda, y acuse, y contraríe, y enseñe, y humille, y deslumbre, y por eso ame con un amor que constantemente se alimenta de estos modos ondulantes, como la lumbre se nutre de los vientos contrarios! Así, el facundo Ulises se desahogaba, ante la copa de oro vacía, y serenamente la diosa escuchaba, con una sonrisa taciturna, y las manos inmóviles sobre el regazo, enroscadas en la punta del velo.

Mientras tanto, Febo Apolo bajaba hacia occidente; y ya de las ancas de sus cuatro caballos sudorosos subía y se esparcía sobre el mar un vapor rubro y dorado. En breve los caminos de la isla se cubrían de sombras. Y sobre los velos preciosos del lecho, al fondo de la gruta, Ulises, sin deseo, y la diosa, que lo deseaba, gozaron el dulce amor, y después el dulce sueño.

Temprano, apenas Eos entreabría las puertas del ancho Urano, la divina Calipso, que se había revestido con una túnica más blanca que la nieve del Pindo, y sujetado a sus cabellos un velo transparente y azul como el éter ligero, salió de la gruta, trayendo al 
magnánimo Ulises, ya sentado a la puerta, bajo las ramas, ante una copa de vino claro, el hacha poderosa de su padre ilustre, toda de bronce, con dos filos y un recio mango de olivo cortado en las faldas del Olimpo.

Limpiando rápidamente la dura barba con el dorso de la mano, el héroe arrebató el hacha venerable:

— ¡Oh diosa, hace cuántos años no toco un arma o una herramienta, yo, devastador de ciudades y constructor de naves!

La diosa sonrío. E, iluminado el rostro franco, con palabras aladas:

-Oh Ulises, vencedor de hombres, si tú te quedases en esta isla, yo encargaría para ti, a Vulcano y a sus forjas en el Etna, armas maravillosas...

— ¿De qué valen armas sin combates u hombres que las admiren? Por lo demás, oh diosa, ya batallé mucho, y mi gloria entre las generaciones está soberbiamente segura. Solo aspiro al suave reposo, vigilando mis ganados, concibiendo sabias leyes para mis pueblos... ¡Sé benévola, oh diosa, y muéstrame los árboles fuertes que me conviene cortar!

En silencio, ella caminó por un atajo, florido de altas y radiantes azucenas, que conducía a la punta de la isla más tupida de vegetación, por el lado de Oriente, y detrás seguía el intrépido Ulises, con la brillante hacha en el hombro. Las palomas dejaban los ramos de cedros, o las concavidades de las rocas en las que bebían, para revolotear en torno a la diosa en un tumulto amoroso. Un aroma más delicado, cuando ella pasaba, subía de las flores abiertas, como de incensarios. El césped que la orla de su túnica rozaba reverdecía en una lozanía más fresca. Y Ulises, indiferente a los prestigios de la diosa, impaciente con la serenidad divina de sus andares armoniosos, meditaba la lancha, suspirando por el bosque. Denso y oscuro lo divisó al fin, poblado de robles, de viejísimas tecas, de pinos que rozaban sus ramas en el alto éter. De su orla descendía un arenal al que ni concha, ni vástago quebrado de coral, ni pálida flor de cardo marino, deshacía la dulzura perfecta. Y el mar refulgía con un brillo de zafiro, en la quietud de la mañana blanca y colorada. Caminando de los robles a las tecas, la diosa marcó al atento Ulises los troncos secos, robustecidos por soles sin número, que fluctuarían, con levedad más segura, sobre las aguas traidoras. Después, acariciando el hombre del héroe como otro árbol robusto también botado a las aguas crueles, se retiró a su gruta, en donde tomó su rueca de oro, y todo el día hiló, y todo el día cantó...

Con alborozada y soberbia alegría, Ulises lanzó el hacha contra un basto roble, que gimió. Y en poco tiempo toda la isla retumbaba, en el fragor de la obra sobrehumana. Las gaviotas, adormecidas en el silencio eterno de aquellas márgenes, levantaron el vuelo en 
amplios bandos, espantadas y gritando. Las fluidas divinidades de los riachuelos indolentes, estremeciéndose en un fulgente escalofrío, huían hacia los cañaverales y las raíces de los alisos. En ese corto día, el valiente Ulises taló veinte árboles, robles, pinos, tecas y chopos; y todos los podó, escuadró y alineó sobre la arena. Su cuello y su curvado pecho humeaban de sudor cuando se retiró pesadamente a la gruta, para saciar el hambre rudo y beber la cerveza helada. Y nunca él había parecido tan bello a la diosa inmortal que, sobre el lecho de pieles preciosas, apenas los caminos se cubrieron de sombra, encontró, sin cansancio y preparada, la fuerza de aquellos brazos que habían derribado veinte troncos.

Así, durante tres días trabajó el héroe.

Y, como arrebatada en esa actividad frenética que agitaba la isla, la diosa ayudaba a Ulises, conduciendo desde la gruta hasta la playa, en sus manos delicadas, las cuerdas y los clavos de bronce. Las ninfas, por mandato suyo, abandonando las tareas suaves, tejían una tela fuerte, para la vela que empujarían con amor a los vientos amables. Y la intendenta venerable ya llenaba los odres de vinos con cuerpo, y preparaba con generosidad los víveres numerosos para la travesía incierta. Mientras tanto, la lancha crecía, con los troncos bien unidos, y un banco levantando en medio, en donde se empinaba el mástil, desbaratado de un pino, más redondo y liso que una vara de marfil. Cada tarde, la diosa, sentada en una roca a la sombra del bosque, contemplaba al calafate admirable martilleando furiosamente, y cantando, con gran alegría, un canto de remador. Y ligeras en las puntas de los pies lustrosos, entre la arboleda, las ninfas, escapando a la tarea, acudían a espiar, con deseosos ojos fulgurantes, aquella fuerza solitaria, que soberbiamente, en el arenal solitario, iba construyendo una nave.

IV

Dor fin, al cuarto día, por la mañana, Ulises acabó de escuadrar el timón, que reforzó
con rejas de aliso para soportar mejor el embate de las olas. Después añadió un lastre abundante, con la tierra de la isla inmortal y sus delicadas piedras. Sin descanso, con un ansia risueña, amarró a la verga alta la vela cortadas por las ninfas. Sobre pesados rollos, maniobrando la palanca, rodó la lancha inmensa hasta la espuma de la ola, con un esfuerzo sublime, los músculos tan tensos y las venas tan hinchadas que él mismo parecía hecho de 
troncos y cuerdas. Una punta de la lancha arfó, levantada en cadencia por la ola armoniosa. Y el héroe, levantando los brazos brillantes de sudor, alabó a los dioses inmortales.

Entonces, como la obra acabara y la tarde rebrillara, propicia a la partida, la generosa Calipso trajo a Ulises, a través de las violetas y de las anémonas, a la fresca gruta. Con sus divinas manos lo bañó en una concha de nácar, y lo perfumó con esencias sobrenaturales, y los vistió con una túnica hermosa de lana bordada, y lanzó sobre sus hombros un manto impenetrable a las neblinas del mar, y le extendió sobre la mesa, para que saciase su hambre ruda, las comidas más sanas y más finas de la tierra. El héroe aceptaba los amorosos cuidados, con paciente magnanimidad. La diosa, con gestos serenos, sonreía taciturnamente.

Después, ella tomó la mano velluda de Ulises, palpando con gusto los callos que le dejara el hacha; y por la orilla del mar lo condujo a la playa, en donde la ola mansamente lamía los troncos de la lancha fuerte. Ambos descansaron sobra una roca musgosa. Nunca la isla había resplandecido con una belleza tan serena, entre un mar tan azul, bajo un cielo tan ameno. Ni el agua fresca del Pindo bebida en marcha abrasadora, ni el vino dorado que producen las columnas de Quíos, eran más dulces de sorber que aquel aire impregnado de aromas, compuesto por los dioses para el respirar de una diosa. La frescura perdurable de los árboles entraba en el corazón, casi pedía la caricia de los dedos. Todos los rumores, el de los regatos en el césped, el de las olas en el arenal, el de las aves en las sombras frondosas, subían, suave y finamente fundidos, como las armonías sagradas de un templo distante. El esplendor y la gracia de las flores retenían los rayos pasmados del Sol. Tantos eran los frutos en los vergeles, y las espigas en las mieses, que la isla parecía ceder, hundida en el mar, el peso de la abundancia.

Entonces la diosa, al lado del héroe, levemente suspiró, y murmuró con una sonrisa alada:

— ¡Oh magnánimo Ulises, tú ciertamente partes! El deseo te lleva a reencontrar a la mortal Penélope, y a tu dulce Telémaco, que dejaste en brazos del ama cuando Europa corrió contra Asia, y ahora ya sustenta en la mano una lanza temida. Siempre de un amor antiguo, con raíces hondas, brotará más tarde una flor, incluso triste. ¡Pero dime! Si en Ítaca no te esperase la esposa tejiendo y destejiendo la tela, y le hijo ansioso que extiende sus brazos incansables hacia el mar, ¿¿dejarías tú, oh hombre prudente, esta dulzura, esta paz, esta abundancia y belleza inmortal?

El héroe, al lado de la diosa, extendió el brazo poderoso como en la Asamblea de los Reyes, ante los muros de Troya, cuando plantaba en las almas la verdad persuasiva: 


\section{KRISTHIAN AYALA}

— ¡Oh diosa, no te escandalices! ¡Pero aunque no existiese, para llevarme, ni hijo, ni esposa, ni reino, yo afrontaría alegremente los mares y la ira de los dioses! Porque, de verdad, oh diosa muy ilustre, mi corazón saciado ya no soporta esta paz, esta dulzura y esta belleza inmortal. Considera, oh diosa, que en ocho años nunca vi el follaje de estos árboles amrillear y caer. Nunca este cielo rutilante se cargó ni de nubes oscuras; ni tuve la satisfacción de extender, bien abrigado, las manos a la dulce lumbre, mientras la borrasca gruesa golpeaba los montes. ¡Todas esas flores que brillan en los tallos airosos son las mismas, oh diosa, que admiré y respiré la primera mañana que me mostraste estos prados perpetuos, y hay lirios que odio, con odio amargo, por la impasibilidad de su albura eterna! ¡Estas gaviotas repiten tan incesantemente, tan implacablemente, su vuelo armonioso y blanco, que yo escondo de ellas el rostro, como otros lo esconden de las negras Arpías! ¡Y cuántas veces me refugio en el fondo de la gruta, para no escuchar el murmullo siempre lánguido de estos arroyos siempre transparentes! Considera, oh diosa, que en tu isla nunca encontré un charco, un tronco podrido, la carcasa de un bicho muerto y cubierto de moscas zumbadoras. Oh diosa, hace ocho años, ocho años terribles, que estoy privado de ver el trabajo, es esfuerzo, la lucha y el sufrimiento... ¡Oh diosa, no te escandalices! Ando hambriento por encontrar un cuerpo arqueando bajo un fardo, dos bueyes humeantes tirando de un arado; hombres que se injurien al pasar un puente; los brazos suplicantes de una madre que llora; un cojo, sobre su muleta, mendigando a la puerta de los pueblos... Diosa, hace ocho años que no veo una sepultura... ¡No puedo más con esta serenidad sublime! Toda mi alma arde en el deseo de lo que se deforma, y se ensucia, y se despedaza, y se corrompe... ¡Oh diosa inmortal, me muero con saudades de la muerte!

Inmóvil, las manos inmóviles en el regazo, enroscadas en las puntas del velo amarillo, la diosa había escuchado, con una sonrisa serenamente divina, la furiosa queja del héroe cautivo... Mientras tanto, ya por la colina, las ninfas, siervas de la diosa, bajaban, trayendo en la cabeza, y amparándolos con el brazo redondo, los jarros de vino, las bolsas de cuero, que la intendenta venerable mandaba para abastecer la barca. Silenciosamente, el héroe colocó una tabla desde la arena hasta el borde de los altos troncos. Y mientras las ninfas pasaban, ligeras, sobre ella, con las anillas de oro tintineando en los pies relucientes, Ulises, atento, contando las bolsas y los odres, gozaba en su noble corazón la abundancia generosa. Pero, amarrados con cuerdas a las clavijas aquellos fardos excelentes, todas las ninfas, lentamente, se sentaron sobre el arenal en torno a la diosa, para contemplar la despedida, el embarque, las maniobras del héroe sobre el dorso de las aguas... Entonces una 
cólera centelleó en los grandes ojos de Ulises. Y, ante Calipso, cruzando furiosamente los valientes brazos:

-Oh diosa, ¿piensas tú de verdad en que nada me falte para que yo suelte vela y navegue? ¿¿Dónde están los ricos presentes que me debes? Ocho años, ocho duros años, fui el huésped magnífico de tu isla, de tu gruta, de tu lecho... ¡Siempre los dioses inmortales determinaron que a los huéspedes, en el momento amigo de la partida, se les ofrezcan considerables regalos! ¿Dónde están, oh diosa, esas riquezas abundantes que me debes por costumbre de la tierra y ley del cielo?

La diosa sonrió, con sublime paciencia. Y en palabras aladas, que huían en la brisa:

— ¡Oh Ulises, tú eres claramente el más interesado de los hombres! Y también el más desconfiado, pues supones que una diosa negaría los presentes debidos a aquel que amó... Calma, oh sutil héroe... Los ricos presentes no tardan, con largueza y brillantez.

Y, ciertamente, por la colina suave, otras ninfas bajaban, ligeras, los velos ondeando, trayendo en los brazos alhajas lustrosas, que al sol rutilaban. El magnánimo Ulises extendió las manos, los ojos devoradores... Y mientras ellas pasaban sobre la tabla crujiente, el héroe astuto contaba, valoraba en su noble espíritu los escabeles de marfil, los rollos de telas bordadas, los cántaros de bronce labrado, los escudos tachonados de piedras...

Tan rico y bello era el jarrón de oro que la última ninfa sustentaba al hombro, que Ulises la detuvo, arrebató el jarrón, lo sopesó, lo miró, y gritó, con soberbia risa estridente:

— iRealmente, este oro es bueno!

Después de colocadas y sujetas bajo el ancho banco las alhajas preciosas, el impaciente héroe, arrebatando el hacha, cortó la cuerda que ataba la lancha al tronco de un roble, y saltó a la alta borda que la espuma envolvía. ¡Pero entonces recordó que ni había besado a la generosa e ilustre Calipso! Rápido, retirando el manto, saltó a través de la espuma, corrió por la arena, y posó un beso sereno en la frente aureolada de la diosa. Ella sujetó levemente su hombro robusto:

- iCuántos males te esperan, oh desgraciado! Mejor sería que te quedases, para toda la inmortalidad, en mi isla perfecta, entre mis brazos perfectos...

Ulises retrocedió, con una exclamación magnífica:

— ¡Oh diosa, el irreparable y supremo mal está en tu perfección!

Y a través de la ola, huyó, trepó ansiosamente a la barca, soltó la vela, surcó el mar, partió hacia los trabajos, hacia las tormentas, hacia las miserias: ja la delicia de las cosas imperfectas! 